\title{
Phylogenetic And Sequence Variability Analyses of Vp1 Protein Of Foot And Mouth Disease Viruses In Cattle In Amhara Region Of Ethiopia
}

Metages Yirgalem ( $\sim$ ymetages257@gmail.com )

Haramaya University, Ethiopia https://orcid.org/0000-0003-0959-3423

Fufa Dawo

Addis Ababa University

Daniel Gizaw

National Animal Health Diagnosis and Investigation Center

Bedaso Mamo

Addis Ababa University College of Health Sciences

Tsion Bilata

National Animal Health Diagnosis and Investigation Center

Dereje Shegu

Yamazaki Dobutsu Kango Daigaku

Research article

Keywords: FMD, Outbreak, Phylogenetic analysis, Serotype O FMD virus, VP1 sequence

Posted Date: January 8th, 2020

DOI: https://doi.org/10.21203/rs.2.20380/v1

License: (9) (i) This work is licensed under a Creative Commons Attribution 4.0 International License.

Read Full License 


\section{Abstract}

Background: Foot-and-mouth disease (FMD) is one of the contagious and the most economically devastating viral diseases caused by the FMD virus. The present study was conducted with the aim of molecular characterization of the FMD virus isolated from outbreaks that occurred in cattle in two different districts of Amhara regional state of Ethiopia. Samples collected from outbreaks were isolated on BHK-21 cell and serotype were detected using antigen detection ELISA. Phylogenetic and amino acid variability analyses of isolated viruses were undertaken after sequencing the VP1 gene in World Reference Laboratory, Pirbright, UK.

Result: In the present study only serotypes 0 was found in the samples analysed using antigen detection ELISA and in 10 out of 13 (76.9\%) cultured samples, virus were isolated on BHK-21 cells. Phylogenetic analysis of these isolates revealed that, they belonged to East Africa topotype-3 (EA-3) and shared 96.6\% nucleotide similarity with Sudan's isolates. A total of $10.3 \%$ amino acid variations were recorded between VP1 gene sequences of the field isolates of serotype O FMDV and vaccine strain (O/ETH/38/2005) used in Ethiopia for vacccine production.

Conclusion: The phylogenetic analysis serotype 0 detected in this study revealed that the virus was clustered with East African topotype-3 (EA-3) and exhibited high genetic similarity with isolates from Sudan. A number of amino acid variations were also noted at different sites of VP1 gene when comparing field isolates with the vaccine strain. Thus, to enhance control of FMD in Ethiopia, detailed molecular analysis of the field isolates along with in-vitro vaccine matching tests need to be undertaken at frequent intervals to assess the protective potential of the vaccine strain in use.

\section{Background}

Foot and Mouth Disease (FMD) is a globally important contagious viral disease affecting cloven-hoofed animals, and the disease is caused by the FMD virus (FMDV). The FMDV is non-enveloped icosahedral virus grouped under the genus Aphthovirus in the family Picornaviridae and possesses positive-sense single-stranded RNA genome. The viral genome is about $8.3 \mathrm{~kb}$ long and enclosed in capsid protein. The capsid comprises 60 copies each of the four structural viral proteins namely VP1, VP2, VP3 and VP4, out of which the first three proteins are directly involved in antigenicity and located on virion surface, while VP4 is internal [1-3]. These three proteins contribute to the formation of five antigenic sites in serotype 0 [4] and four known antigenic sites in serotype $A[1,5]$. Generally, the virus has got seven immunogenically distinct serotypes, namely, O, A, C, SAT1, SAT2, SAT3 and Asia1 [6-9]. Within each serotype, many subtypes can be identified by molecular and immunological tools $[7,10]$. This genetic heterogeneity of the virus mainly occurred due to error-prone replication which improves viral fitness by changing antigenically important sites of the virus that enabled them to escape from protection by the developed vaccine [11]. 
In Ethiopia, five of the seven known serotypes (O, A, C, SAT1, SAT2) were reported in bovine, swine, ovine, and caprine samples collected from different outbreaks which occurred from 1981-2007 [12] . From this report, serotype 0 was found to be the most predominant strain circulating in the country $(73.3 \%)$ followed by serotype A (19.5\%), SAT $2(4.1 \%)$ and SAT1 (1.8\%). However serotype C was not isolated in Ethiopia after 1983 [12]. The East Africa topotype (EA-3) [13, 14] and EA-4 [14] of serotype 0 and Africa topotype (G-VII) [14] and Africa topotype (G-IV) [15] of serotype A were circulating in the country.

Foot and mouth disease is one of the most important livestock diseases in the world in terms of its economic impact [16]. The annual economic impact of FMD in terms of visible production losses and vaccination costs in endemic regions of the world is estimated between US\$ 6.5 and 21 billion, while outbreaks in FMD free countries and zones cause losses of more than US\$1.5 billion a year [17]. The presence of FMD in Ethiopia leads to considerable economic losses through production loss, morbidity and mortality of affected animals $[16,18,19]$. The economic losses of FMD outbreaks in this country due to milk loss, draft power loss and mortality were on average USD 76 per affected herd and USD 9.8 per head of cattle in the affected herds in crop-livestock mixed system; and USD 174 per affected herd and USD 5.3 per head of cattle in the affected herds in the pastoral system [20]. The diseases also the major constraint hampering the export of livestock and livestock products to the Middle East and African countries; the Egyptian trade ban of 2005, in which Ethiopia lost more than US\$14 million [21]

Phylogenetic analysis of the VP1 region of FMD viruses has been used to study the genetic relationships between different FMD virus isolates, geographical distribution of lineages and genotypes, the establishment of geographically and genetically linked topotypes and tracing the source of virus during outbreaks [9]. Topotypes are geographically clustered viruses in a single genetic lineage and sharing $>85 \%$ (O, A, C, and Asia 1) or >80\% (SAT 1, SAT 2, and SAT 3) nucleotide similarity in the VP1-coding region [22]. VP1 nucleotide sequences are used for reconstructing the evolutionary history of organisms and molecular evolutionary studies [9].

Although animals are protected against FMD by the Government through vaccination in Ethiopia, lack of vaccination strategies and presence of free animal movement without certification are the main factors that could increase the spread of FMD. Moreover, lack of veterinary infrastructure to handle outbreaks on large scale greatly contributes to the increasing occurrence of the disease [12]. The detailed research work on serotyping and molecular phylogeny of FMD in the present study area is needed to determining the circulating serotype(s), establishing the geographic relatedness between isolates and molecular evolution of the virus for planning a proper control and preventive measure in the country. 
Therefore, the objective of the present study was to undertake phylogenetic analysis on virus circulating in the study area and to determine the amino acid sequence similarity/variability between the VP1 protein of the field isolate and the vaccine strain isolate (O/ETH/38/2005 with the Accession number FJ798108) $[23,24]$ currently in use for vaccine production in Ethiopia.

\section{Results}

\section{Virus isolation}

Out of 21 samples collected 13 representative samples from each outbreak were subjected to virus isolation using Baby Hamster Kidney (BHK-21) monolayer cell culture. From 13 samples cultured, cytopathic effect (CPE) was observed in $10(76.9 \%)$ samples (Table 1), while virus did not grow on the rest of the three samples even when blind passaged three times. The CPE observed was fast destruction of mono-layer cells and the infected cell appeared as singly and round in shape. Additionally, the CPE was characterized by complete destruction of the cell and cell detachment which was mostly seen within 48 hrs of inoculation.

\section{- Serotype identification}

All the 21 samples were subjected to serotype differentiation using antigen detection sandwich ELISA and only serotype 0 was detected (Table 1), indicating that this serotype was the predominant in the study area. The same serotype was found in both Shewarobit and South Wollo areas of Amhara regional state.

Table 1: Result of FMDV serotyping by antigen detection ELISA and virus isolation by BHK-21 cell 


\begin{tabular}{|c|c|c|c|c|c|}
\hline $\begin{array}{l}\text { Site of } \\
\text { outbreak }\end{array}$ & Kebele & $\begin{array}{l}\text { No. of sample } \\
\text { inoculated }\end{array}$ & $\begin{array}{l}\text { Type of samples } \\
\text { inoculated }\end{array}$ & Virus isolated & $\begin{array}{l}\text { Serotype } \\
\text { detected }\end{array}$ \\
\hline & Yelen & 4 & 3Tissue and 10P & ETH/17/18 & 0 \\
\hline \multirow[t]{4}{*}{ Shewarobit } & & & & $\mathrm{ETH} / 20 / 18$ & \\
\hline & & & & $\mathrm{ETH} / 23 / 18$ & \\
\hline & Kewet & 3 & Tissue & ETH/24/18 & 0 \\
\hline & & & & $\mathrm{ETH} / 27 / 17$ & \\
\hline South & Albeko & 2 & Tissue & ETH/35/18 & 0 \\
\hline \multirow[t]{3}{*}{ Wollo } & & & & ETH/36/18 & \\
\hline & Werebabo & 4 & Tissue & $\begin{array}{l}\text { ETH/37/18 } \\
\text { ETH/39/18 }\end{array}$ & 0 \\
\hline & & & & ETH/41/18 & \\
\hline
\end{tabular}

\section{Phylogenetic analysis}

From the FMD viruses isolated, amplicons corresponding to the complete VP1 coding region were generated by reverse transcription (RT-PCR) and the sequence data were generated for 9 of the serotype 0 FMD viruses in WRLFMD, Pirbright, UK. The sequence data were used for comparison with other available viral sequences downloaded from NCBI, GenBank to reconstruct phylogenetic relationships of the isolates. List of FMD serotype $\mathrm{O}$ isolates in this study and some selected serotype $\mathrm{O}$ sequences of different countries downloaded from NCBI which are used for comparison are summarized in Table 2 (Additional file 1).

Assessment of phylogenetic analysis of VP1 gene of FMDV serotype 0 isolates (Figure 1) showed that both Shewarobit and South Wollo strains were clustered with other strains belonging to the East African topotype-3(EA3).TheisolatesfromYelen (O/ETH/23/2018, O/ETH/17/2018, and O/ETH/20/201) and Kewet (O/ETH/24/2018 and O/ETH/27/2017) kebele of Shewarobit shared $99.5 \%$ nucleotide identity. Similarly, isolates from Albeko (O/ETH/36/2018 and O/ETH/35/2018) and Werebabo (O/ETH/37/2018 and O/ETH/39/2018) kebeles of South Wollo had only $99.4 \%$ nucleotide similarity. Furthermore, isolate from both outbreak sites (Shewarobit and South Wollo) shared more than $90 \%$ nucleotide similarity with each other. The VP1 sequences FMDV serotype $O$ isolates in the present study were also compared with other Ethiopian and African isolates available in the GenBank database (Figure 1). Accordingly, the isolate O/ETH/17/2018 and O/ETH/24/2018 from Yelen and Kewet kebeles respectively of Shewarobit 
had $7.8 \%$ nucleotide divergence with Ethiopian isolates of O/ETH/3/96 and O/ETH/30/94. However, only $3.4 \%$ nucleotide diversities were recorded when compared to Sudan isolates (O/SUD/3/2008, O/SUD/5/2008 and O/SUD/4/2008 with accession numbers KR149728, GU566061 and KJ831704, respectively) which are genetically homologs on their VP1 gene nucleotide sequence and this is supported by $99 \%$ bootstrap value. The phylogenetic analysis of isolates in this study also showed that, they are differing by $15.7 \%$ with EA-1 (O/UGA/5/96, O/KEN/83/79), $17.1 \%$ with EA-2 (O/KEN/5/2002, O/UGA/3/2002), 21.5\% with EA-4 (O/ETH/58/2005, O/ETH/59/2005) and 22.1\% with WA (O/BKF/1/92, $\mathrm{O} / \mathrm{BKF} / 2 / 92$ ) topotype of FMD serotype 0 virus group.

Figure 1: Minimum-Evolution tree showing the relation between the serotype 0 isolates from Ethiopia and reference viruses. The red rectangle ( ) indicates the new isolates obtained from the outbreak cases of Shewarobit and South Wollo. Bootstrap values $<70 \%$ were not shown in the picture. EA, East Africa; WA; West Africa.

Sequence-based comparison of Serotype $O$ isolates with the vaccine strain $(0 / E T H / 38 / 2005)$

The VP1 sequence of serotype 0 field isolates were compared with the VP1 sequence of vaccine strain currently used for vaccine production in Ethiopia to determine their genetic relationship. Out of the total 639 nucleotides compared, 107 (17\%) variable sites were detected between VP1 sequence of the vaccine strain and serotype 0 isolate from Shewa Robit and South Wollo, while 532 (83\%) were conserved over the region as shown in Figure 4 (Additional file 2). Most of these nucleotide variations (71.03\%) were noticed at $3^{\text {rd }}$ codon positions, while $18.69 \%$ and $10.28 \%$ nucleotide variations occurred in the $1^{\text {st }}$ and $2^{\text {nd }}$ codon positions, respectively. The deduced amino acid sequences were also aligned and investigated in an attempt to determine the amino acid variations. A total of 22 out of $213(10.3 \%)$ amino acid variations were observed in different sites of the VP1 gene, while the remaining $89.7 \%$ amino acids (aa) were conserved with reference to the vaccine strain. The variations were predominantly observed in two distinct regions, comprising the G-H loop (aa positions 133-158) and the C-terminus (aa positions 194213), reported to be the main immunogenic sites of VP1 $[9,24]$. The amino acid substitutions at various positions obseved in the vaccine strain and field isolates, respectively, were (Figure 2): 133 asparagine (N) $\rightarrow$ serine $(S), 138$ valine $(V) \rightarrow$ glutamate $(E), 139$ threonine $(T) \rightarrow$ alanine $(A), 140$ serine $(S) \rightarrow$ arginine $(R), 141$ valine $(V) \rightarrow$ alanine $(A), 142$ threonine $(T) \rightarrow$ alanine $(A), 158$ proline $(P) \rightarrow$ threonine $(T), 197$ serine $(S) \rightarrow$ alanine $(A)$ and 198 glutamate $(E) \rightarrow$ glycine $(G)$ amino acid. At the position 134, majority of 
the isolates including the vaccine strain in the present study, contained amino acid cysteine (C) except, isolates $\mathrm{O} / \mathrm{ETH} / 23 / 2018$ and $\mathrm{O} / \mathrm{ETH} / 24 / 2018$, which had glycine (G). However, an amino acid change was also observed in antigenic site three at position 45 [25] , wherein threonine (T) was replaced by glutamine (Q). Interestingly, the Arginine-Glycine-Aspartate (RGD) cell attachment sites within the G-H loop of the gene, at position 145-147 were conserved in all the isolates including the vaccine strain.

$\begin{array}{lllll}10 & 20 & 30 & 40 & 50\end{array}$

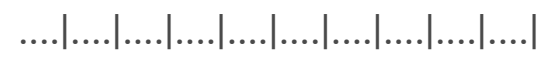

O/ETH/38/2005 VP1/FJ798108 TTSPGESADPVTATVENYGGETQVQRRQHTDVSFILDRFVKVTPTDQINV

O/ETH/27/2017

O/ETH/17/2018

O/ETH/20/2018

O/ETH/23/2018

O/ETH/24/2018

O/ETH/35/2018

O/ETH/36/2018

O/ETH/37/2018

O/ETH/39/2018

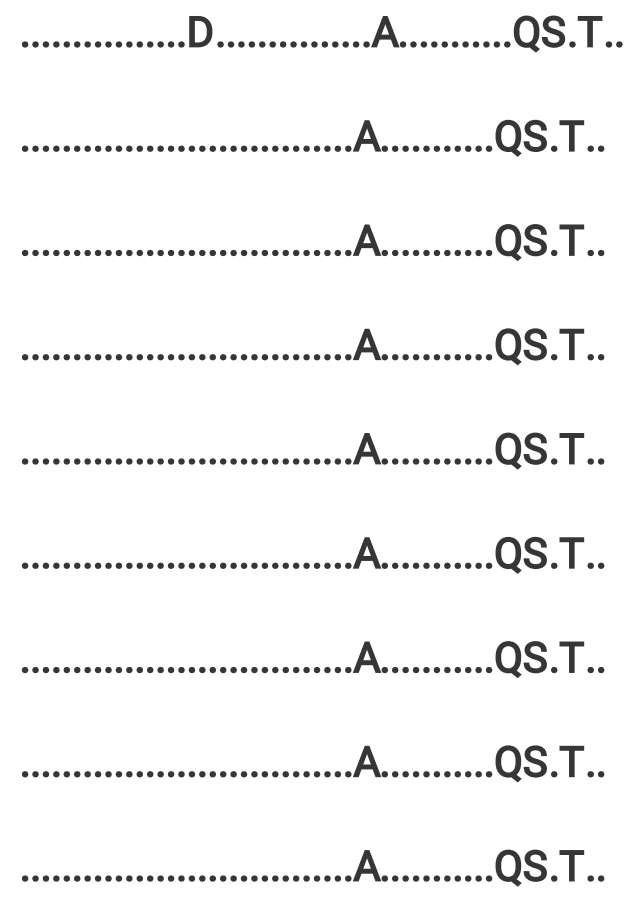

$\begin{array}{lllll}60 & 70 & 80 & 90 & 100\end{array}$

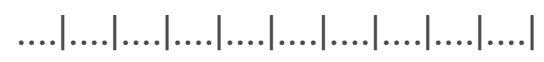

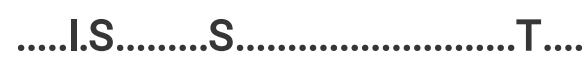

O/ETH/17/2018 


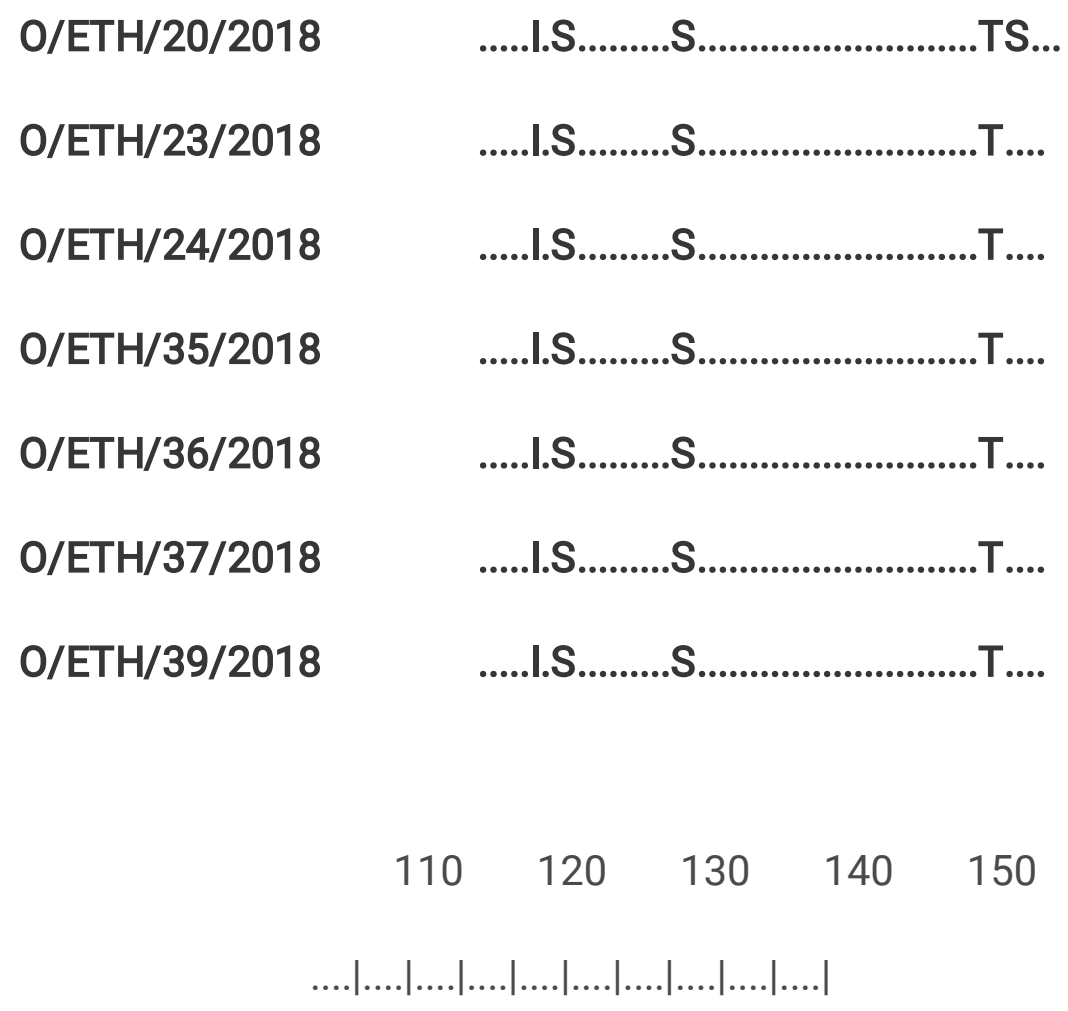

O/ETH/38/2005 VP1/FJ798108 TTNPTAYHKAPLTRLALPYTAPHRVLATVYNGNCKYGVTSVTNVRGDLQV

O/ETH/27/2017

O/ETH/17/2018

O/ETH/20/2018

O/ETH/23/2018

O/ETH/24/2018

O/ETH/35/2018

O/ETH/36/2018

O/ETH/37/2018

O/ETH/39/2018

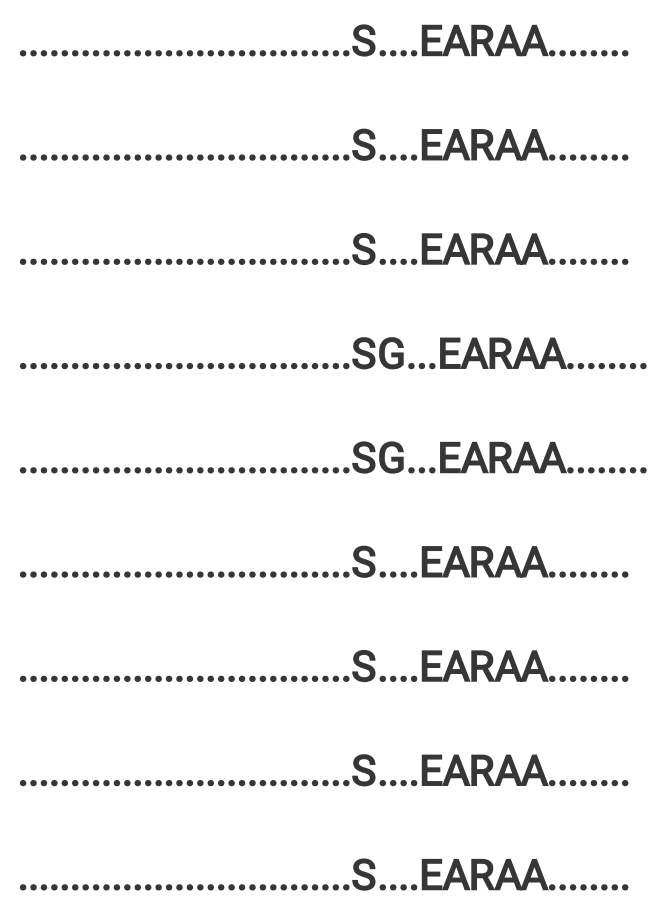

$\begin{array}{lllll}160 & 170 & 180 & 190 & 200\end{array}$ 


\begin{tabular}{|c|c|}
\hline O/ETH/27/2017 & ...V.T...AG.. \\
\hline O/ETH/17/2018 & 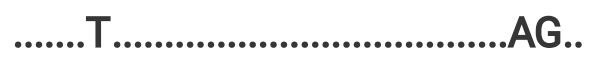 \\
\hline O/ETH/20/2018 & 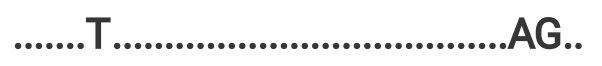 \\
\hline O/ETH/23/2018 & 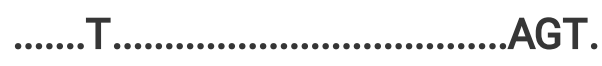 \\
\hline O/ETH/24/2018 & ......T.......................................... \\
\hline O/ETH/35/2018 & 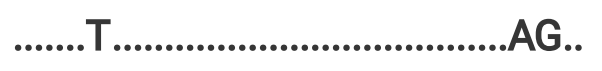 \\
\hline O/ETH/36/2018 & 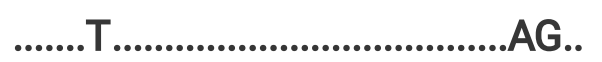 \\
\hline O/ETH/37/2018 & 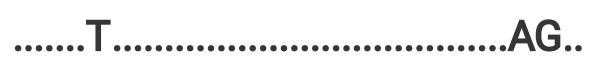 \\
\hline O/ETH/39/2018 & ........T.................... \\
\hline
\end{tabular}

\section{O/ETH/38/2005 VP1/FJ798108 HKQKIVAPVKQLL}

O/ETH/27/2017

O/ETH/17/2018

O/ETH/20/2018

O/ETH/23/2018

O/ETH/24/2018

O/ETH/35/2018

O/ETH/36/2018

O/ETH/37/2018

O/ETH/39/2018

Figure 2: Amino acid sequence alignments of the VP1 gene of vaccine strain (O/ETH/38/2005) with serotype $\mathrm{O} F \mathrm{FD}$ field isolates. The amino acid sequence of the vaccine strain is written on top row and the conserved amino acids are indicated by dots of different colors.

\section{Discussion}


Results of the present study indicated that only serotype 0 of FMD viruses was circulating in the study area. Phylogenetic reconstruction based on VP1 sequence data showed that these viruses were grouped under East Africa topotype- 3 (EA-3).

From 13 samples cultured on BHK-21 cell, cytopathic effect (CPE) was observed in 10 (76.9\%) samples. In the rest 3 samples virus did not grow even at third blind passage. This may be probably because these were oro-pharyngeal samples collected from animals that had previous history of the disease and at early stage of recovery during sample collection. This suggested that the chances of virus isolation from tissue samples taken from old lesion (in recovery stage) and oro-pharyngeal fluid samples were less due to lower concentration of the virus. In agreement with the present findigs, OIE [10] also recommended that the preferred sample for virus isolation is epithelial tissue from unruptured or freshly ruptured vesicles. In isolated virus, the CPEs observed were characterized by single appearance, rounding, detachment as well as destruction of mono-layer cell. This result is in line with previous reports $[26,27,15]$ in which, FMDV growth on BHK-21 cell, characterized by fast destruction of monolayer cells and infected cells appeared singly and round in shape.

The serotype identification in the present study area revealed that FMDV serotype 0 was the only identified and predominant serotype, which is in agreement with the reports made earlier in different regions of Ethiopia [12, 15, 26, 27, 28, 29]. Sequence coding for the FMDV VP1 protein has been used extensively to investigate the relationship between different isolates of the virus worldwide [30]. On the basis of VP1 gene sequence comparison, existence of 8 serotype 0 topotypes has been confirmed within samples collected around the World. Out of the 8 topotypes, only 2 were found in Africa, with one each in East and West Africa [22]. FMD viruses with $>95 \%$ of nucleotide similarity in the VP1 sequence were considered as closely related [30], while those virus serotypes $(\mathrm{O}, \mathrm{A}, \mathrm{C})$ with $>85 \%$ nucleotide similarity were clustered in a single genetic lineage [12]. It is also assumed that FMD viruses that differ between 2$7 \%$ from each other are generally believed to originate from the same epizootic [31]. Thus, VP1 sequences analysis of the current serotype 0 isolates from Shewarobit and South Wollo revealed that they were clustered in East Africa Topotype III (EA-3) and shared above $92 \%$ nucleotide identity with the virus $\mathrm{O} / \mathrm{ETH} / 3 / 96$ and O/ETH/30/94 which grouped under this lineage. In agreement with this finding, East Africa Topotype - 3 (EA-3) of serotype O FMDV was reported from the different parts of Ethiopia by different authors based on comparison of VP1 gene sequence $[12,14,26,27]$. The isolates from these two sites had $99.3 \%$ nucleotide similarity which is $<5 \%$ indicating the viruses in both areas were closely related and they probably originated from the same source. In addition, isolates O/ETH/17/2018 and O/ETH/24/2018 shared $96.6 \%$ nucleotide identity with Sudan isolates of 2008 (O/SUD/3/2008, O/SUD/5/2008 and O/SUD/4/2008). This finding was similar to previous report that showed serotype 0 FMDV isolates of Ethiopia and Sudan had high genetic similarity. As the report indicated that, they had about $95.31 \%$ nucleotide similarity between isolate O/ETH/59/2011 from Ethiopia and O/SUD/3/2008, O/SUD/4/2008 and O/SUD/3/2008 isolates from Sudan [32].

In the present study, the serotype identified was (serotype 0) high nucleotide similarity with that of Sudan isolates suggesting that the outbreaks in Ethiopia occurred probably because of uncontrolled trans- 
boundary animal movement. Such uncontrolled animal movements have a big risk on the transmission of the virus across the border in both directions, in addition to the the ability of the virus to transmit via wind. Similar observation was reported by Sanger [33], which reported the presence of trans-boundary and trans-continental transmission of viruses in west and southern Africa. Samuel et al. [34] also reported, closely related viruses could either be from the same outbreak or from viruses temporally closely related.

In the present study, the deduced nucleotide and amino acid sequences were aligned and investigated in an attempt to determine the variation. Hence, a total of 107 out of $639(17 \%)$ nucleotides and 22 out of $213(10.3 \%)$ amino acid changes were noted at the VP1 gene of field isolate when compared to the vaccine strain. Most of these variations have occurred in G-H loop at positions 133-158 and the Cterminus region at positions 194-213, known to be an immunodominant region of VP1 gene [24]. In an other report, the amino acid site from 141-160 was found to be the imunodominant region of serotype 0 of FMDV [4]. The existence of even small genetic variation in the immunodominant regions can alter the antigenic specificity of FMD viruses [9]. Thus, in the present study, the existence of amino acid variation especially at immunodominant region indicates the need for in-vitro vaccine matching studies at frequent intervals to establish the level of protection conferred by the strains available in the vaccine against the currently circulating viruses. These changes have implications in vaccine strain selection as these changes occurred in G-H loop as compared with the vaccine strain in use in Ethiopia.

\section{Conclusions}

In the present study, serotype $\mathrm{O}$ was identified and isolated on BHK-21 cell culture from the different outbreaks and found as the dominant serotype circulating in the study area. The phylogenetic characterization of this serotype revealed that it was clustered with East African topotype-3 (EA-3) and showed higher genetic similarity with serotype $O$ isolates of Sudan (O/SUD/3/2008, O/SUD/5/2008 and $\mathrm{O} / \mathrm{SUD} / 4 / 2008$ ). A number of amino acid variations observed at different sites of VP1 gene including the immunodominant region (133-160, 194-213) indicating the presence of genetic heterogeneity between the isolates in the present study and vaccine strain. Hence, further molecular analyses of the who gene coupled with protection potential of the existing vaccines against the isolates should be performed at regular intervals.

\section{Methods}

\section{Study areas}

The study was conducted from October 2017 to May 2018 in Shewarobit and South Wollo districts of Amhara regional states of Ethiopia. Shewarobit is a town in KewetWoreda having a tropical climate with an average temperature of $23.0^{\circ} \mathrm{C}$. South Wollo is one of ten Zones in the Amhara National Regional 
State of Ethiopia having an average temperature and rainfall of $19.5^{\circ} \mathrm{C}$ and 1185.1 millimeters, respectively [35]. The study areas were selected due to the occurrence of FMD outbreaks in different times. The distribution and density of animal populations vary across agro-ecological zones and woredas even though the distribution follows the pattern of human population. In both study areas animals were mostly reared under extensive management systems although semi-intensive farming is practiced rarely in some kebeles of the area.

Figure 3: Map of study areas

\section{Study animals}

The study was conducted in cattle that had experienced outbreaks of FMD and manifesting the clinical signs of the disease. The animals were owned by farmers in the study area and their consent were asked before starting sampling and sample was collected only from willingness owners. Cattle of all age groups, breed, and sexes reared under semi-intensive and extensive production and management systems were included in the study.

\section{Study Design}

Based on reports of active cases of FMD outbreaks, a cross-sectional study design was employed to collect samples. While active cases were reported, a field investigation was conducted at a particular site of outbreaks within the study districts. Animals with active lesions and those in a history of infection but having healing lesions were used to collect samples for diagnostic purposes and confirmation of the cases.

\section{Sample collection}

A total of 21 FMD suspected samples, 14 epithelial and 7 oro-pharyngeal (OP) samples, were collected from four different outbreaks sites (Yelen, Kewet, Albeko, Werebabo) in the two districts of the region. The epithelial samples were collected aseptically from unruptured and freshly ruptured oral and foot lesions 
from FMD suspected cattle. The samples were immediately placed in a virus transport medium composed of an equal amount of glycerol and $0.04 \mathrm{M}$ of phosphate buffer saline solution (PBS)with antibiotics at $\mathrm{pH}$ 7.2-7.6 [36]. OP sampleswere collected by passing a probang cup into oro-pharyngeal area from previously FMD suspected cattle and asymptomatic cattle that were found in close proximity to the affected herds. The collected fluid samples were examined for its clarity and $2 \mathrm{ml}$ of it containing cellular material were poured into a sampling bottle containing equal amounts of transport media (composed of $0.08 \mathrm{M}$ phosphate buffer containing $0.01 \%$ bovine serum albumin, $0.002 \%$ phenol red, antibiotics), pH7.2-7.4 [36]. The samples were, then, labeled, placed in icebox and transported to National Animal Health Diagnostic and Investigation Center (NAHDIC), Sebeta and stored at $-80^{\circ} \mathrm{C}$ until required for further laboratory investigation.

\section{Virus isolation}

Sample processing and virus isolations on BHK-21 cells were conducted following the procedure of OIE manual [37]. Briefly, the epithelium samples were first taken from the transport media and blotted dry on absorbent paper. Then, a suspension was prepared by grinding the tissue sample in sterile sand in a sterile pestle and mortar with a small volume of tissue culture medium containing antibioticsand antifungal(penicillin [1000 International Units (IU)], neomycin sulphate [100 IU], polymyxin B sulphate [50 IU], amphotericin B [1000x]) and diluted in the same medium to $10 \%$ suspension. Finally, the suspension was clarified on a bench centrifuge at $2000 \mathrm{~g}$ for 10 minutes and filtered by Millipore filter paper of 0.22 $\mu \mathrm{m}$ pore size.About $1 \mathrm{ml}$ of clarified suspensions suspected to contain FMDV were inoculated to baby hamster kidney (BHK-21) cells (AU-PANVAC) in $25 \mathrm{~cm}^{2}$ tissue culture flasks and incubated at $37^{\circ} \mathrm{C}$ for 1 hour for virus adsorption. Afterward, $7 \mathrm{ml}$ of maintenance media (contain $2 \%$ fetal calf serum) of Dulbecco's Modified Eagle's Medium (DMEM) was added and incubated at $37^{\circ} \mathrm{C}$ with $5 \% \mathrm{CO}_{2}$ in a humidified incubator and monitored for cytopathic effect (CPE) every $24 \mathrm{hr}$ for a maximum of 48 hours. When no CPE was observed, blind passaging of the inoculated cells was done by freeze-thawing, clarification by centrifugation and finally inoculated to fresh cell monolayer. Sample was considered negative if no CPE was observed after $48 \mathrm{hrs}$ of the third passage of virus as described by [38]. Finally, isolated samples were labeled and stored at $-80^{\circ} \mathrm{C}$ for further experiments.

\section{Serotype identification}

FMDV serotype was detected and identified from the suspension by using antigen detection sandwich ELISA (IZSLER, Brescia, Italy) according to the manufacturer protocol and the protocol described in the 
OIE Manual for Terrestrial Animals [37]. Briefly, first samples were diluted $1 / 2$ in diluent buffer and $50 \mu \mathrm{l} /$ well of each sample was distributed to 8 wells of a column (a total of 80 wells of A-H rows (each row were coated with FMD serotype-specific monoclonal antibodies)). Then, 50 $\mu$ l of diluents per well were added in all wells including thepositive and negative control wells and plates were incubated at room temperature for 1 hour. After incubation, all the fluid in each well was discarded and the plate was tap hard to remove all the residual fluid. Then $200 \mu$ of washing solution was added and incubated for $3 \mathrm{~min}$ at room temperature, subsequently wells were emptied and the washing repeated twice (three washing cycles in total). Then all residual fluids were removed by tapping on clean absorbent paper and $50 \mu \mathrm{l} /$ well of conjugate $A$ was added from row $A$ to $F$ and the same volume of conjugate $B$ was added into row $\mathrm{G}$ and $\mathrm{H}$. Plates were covered and incubated at room temperature for 1 hour. After incubation $50 \mu \mathrm{l}$ of substrate per well was added to all wells and plates were covered and left at room temperature for 20 minutes in the dark. The reaction was stopped by adding $50 \mu \mathrm{l} /$ well of stop solution (sulfuric acid, $\mathrm{H}_{2} \mathrm{SO}_{4}$ ). Immediately after stopping, reading the optical density (OD) of each well was taken at $450 \mathrm{~nm}$ wavelength using micro plate reader.

\section{Reverse transcription-polymerase chain reaction (RT-PCR) and sequencing}

Ten virus isolates were sent to World Reference Laboratory for FMD (WRLFMD), The Pirbright Institute, Pirbright, United Kingdom, for sequencing the VP1 gene of the FMDV strain according to recommended international standard. All RNA extraction, RT-PCR, and sequencing were conducted in WRLFMD.

\section{Data management and analysis}

Optical density (OD) values of the samples generated from antigen detection ELISA were interpreted by subtracting the OD value of each negative control from the OD value measured for each test sample with the corresponding coated MAb. The results were interpreted as summarized in table 3 (Additional file 3 ).

The generated sequence data were aligned by multiple sequence alignments using the Clustal W algorithm as implemented in BioEdit and MEGA6 software packages to compare the VP1 of outbreaks sequences with other reference sequences retrieved from GenBank. The aligned sequences were used to reconstruct phylogenetic tree using minimum-evolution methods of analysis and maximum likelihood method imbedded in MEGA6 [39] and confidence levels were assessed by 1000 bootstrap replications. Serotypes were distinguished on the basis of nucleotide sequence differences of $30-50 \%$ and high bootstrap support (> 70\%) while a divergence of $15 \%$ distinguishes topotypes [38]. 


\section{Abbreviations}

AU-PANVAC: African Union- Pan African Veterinary Vaccine Centre; BHK: Baby hamster kidney; ${ }^{\circ} \mathrm{C}$ : Degree Celsius; CPE: Cytopathic effect; ELISA: Enzyme linked Immunosorbent assay; FMD: Foot and mouth disease; FMDV: Foot and mouth disease virus; MAb: Monoclonal antibody; NAHDIC: National Animal Health Diagnostic and Investigation Center; NCBI: National Center for Biotechnology Information; OIE: World Organization for Animal Health; OP: Optical density; PBS: Phosphate Buffered Saline; RNA: Ribonucleic Acid; RT-PCR: Real Time Polymerase Chain Reaction; SAT: South Africa territories; UK: United Kingdom; VP: Virus Protein; WRLFMD: World Reference Laboratory for Foot and Mouth Disease.

\section{Declarations}

\section{Acknowledgements}

We would like to thank Minstry of Sceince and Technology of Ethiopia, National Animal Health Diagnostic and Investigation Center and World Reference Laboratory for their support to the study. We would like to thanks also all the study participant especially the staff of National Animal Health Diagnostic and Investigation Center for their cooperation starting from sample collection to sample processing.

\section{Funding}

The cost of this study was covered by National Animal Health Diagnostic and Investigation Center (NAHDIC) and FMD project funded by Ministry of Science and Technology of Ethiopia. The funders had no role in study design, data collection, analysis and interpretation or preparation of the manuscript.

\section{Availability of data and materials}

The datasets used during the current study available from the corresponding author on reasonable request.

\section{Authors' contributions}

MY conceptualized the study, performed sample collection, laboratory and sequence analysis, interpreted the results, and prepared the manuscript. FD and BM assisted with refining the study design and critically reviewed the manuscript. DG, TB and DS assisted with sample collection and laboratory analysis. All authors read and approved the final manuscript.

\section{Ethics approval and consent to participate}

Ethical approval for this study was obtained from Addis Ababa University College of Veterinary Medicine and Agriculture Minutes of Animal Research Ethics and Review Committee on minute number (VM/ERC/05/10/018) with the reference number (VM/ERC/06/05/10/2018). Animal owners also asked 
for their consent verbally before starting sampling. Verbal consent was taken because the Research Ethics Committee approved that the study was not invasive and sample can be collected from animal showing sign of the disease from willingness animal owner.

\section{Consent for publication}

Not applicable.

\section{Competing interests}

The authors declare that they have no competing interests.

\section{Author details}

${ }^{1}$ Haramaya University School Animal and Range Sciences, P.O.Box. 138 Dire Dawa, Ethiopia. ${ }^{2}$ Addis Ababa University College of Veterinary Medicine and Agriculture, P.O.Box 34, DebreZeit, Ethiopia. ${ }^{3}$ National Animal Health Diagnostics and Investigation Center, P.O.Box 04, Sebeta, Ethiopia.

\section{References}

1. Bari FD, Parida S, Tekleghiorghis T, Dekker A, Sangula A, Reeve R, Haydon DT, Paton DJ, Mahapatra $M$. Genetic and antigenic characterization of serotype A FMD viruses from East Africa to select new vaccine strains. Vaccine. 2014;32:5794-5800.doi: 1016/j.vaccine.2014.08.033.

2. Gao Y, Sun SQ, Guo HC. Biological function of Foot-and-mouth disease virus non-structural proteins and non-coding elements. J. 2016;13:107-124.doi: 10.1186/s12985-016-0561-z.

3. Rueckert R and Wimmer E. Systematic nomenclature of picornavirus proteins. J Virol. 1984;59:957959.

4. Aggarwal N, Barnett PV.Antigenic sites of foot-and-mouth disease virus (FMDV): an analysis of the specificities of anti-FMDV antibodies after vaccination of naturally susceptible host species. Gen. Virol.2002; 83:775-782.https://doi.org/10.1099/0022-1317-83-4-775.

5. Kitching RP. Global epidemiology and prospects for control of foot-and-mouth disease. In: Foot-andMouth Disease Virus. Springer. 2005.p.133-148.

6. Balemual A. Review on pathogenesis, economic significance, prevention and controls of foot and mouth disease. AJAD. 2018;7:12-20. 
7. Knowles NJ, Samuel AR. Molecular epidemiology of foot-and-mouth disease virus. Virus 2003;91:6580.https://doi.org/10.1016/ S0168-1702(02)00260-5.

8. Maree FF, Blignaut B, Esterhuysen JJ, De Beer TA, Theron J, O'Neill HG, Rieder E. Predicting antigenic sites on the foot-and-mouth disease virus capsid of the South African Territories types using virus neutralization data. Gen. Virol. 2011;92:2297-2309. doi: 10.1099/vir.0.032839-0.

9. Sahle M, Venter EH, Dwarka RM, Vosloo W. Molecular epidemiology of serotype O Foot-and-mouth disease virus isolated from cattle in Ethiopia between 1979-2001. Onderstepoort Vet. Res. 2004;71:129-138. DOI:10.4102/ojvr.v71i2.275

10. Foot-and-mouth disease, Manual of Standard for Diagnostic Tests and Vaccine for Terrestrial Animals. 6th ed. Paris. 2009. p. 156-212.

11. Grazioli S, Fallacara F, Brocchi E. Mapping of antigenic sites of foot-and-mouth disease virus serotype Asia 1 and relationships with sites described in other serotypes. Gen. Virol. 2013;94: 559569.doi:10.1099/vir.0.048249-0.

12. Ayelet G, Mahapatra M, Gelaye E, Egziabher BG, Rufeal T, Sahle M, Ferris NP, Wadsworth J, Hutchings GH, Knowles N J. Genetic characterization of foot-and-mouth disease viruses, Ethiopia, 1981-2007. Infect. Dis. 2009;15:1409-1417.doi: 10.3201/eid1509.090091

13. Negussie H, Ayelet G, Jenberie S, Minda S, Tesfaw L. Molecular epidemiology and vaccine matching study on foot-and-mouth disease virus circulating in Ethiopia. J. Microbiol. Res. 2013;7:5101-5106.

14. WRLFMD Molecular Epidemiology/Genotyping, OIE/FAO FMD Reference Laboratory Network. Annual Reports. 2016. p. 22-23.

15. Sulayeman M, Dawo F, Mammo B, Gizaw D, Shegu D. Isolation, molecular characterization and seroprevalence study of foot-and-mouth disease virus circulating in central Ethiopia. BMC Res. 2018;14:110.https://doi.org/10.1186/s12917-018-1429-9.

16. James AD, Rushton J. The economics of foot and mouth disease. sci. tech. Off. int. épizoot.2002;21:637-641. DOI:10.20506/rst.21.3.1356.

17. Knight-Jones TDJ and Rushton J. The economic impacts of foot andmouth disease - what are they, how big are they and where do theyoccur? Prev. Vet. Med. 2013;112: 161-173.

18. Baluka SA, Ocaido M, Mugisha A. Prevalence and economic importance of Foot and Mouth Disease, and Contagious Bovine Pleuropneumonia Outbreaks in cattle in Isingiro and Nakasongola Districts of Uganda. Discourse J Agric Food Sci. 2014;2:107-117.

19. Mattion N, Konig G, Seki C, Smitsaart E, Maradei E, Robiolo B, Duffy S, Leon E, Piccone M, Sadir A, Botinni R. Reintroduction of foot-and-mouth disease in Argentina: characterization of the isolates and development of tools for the control and eradication of the disease. Vaccine. 2004;22:41494162.DOI:1016/j.vaccine.2004.06.040.

20. Jemberua WT, Mourits MC, Woldehanna T, Hogeveen H. Economic impact of foot and mouth disease outbreaks on smallholder farmers in Ethiopia. Prev. Vet. Med. 2014;116:26-36.

21. Leforban Y. Report of a mission of foot and mouth misease In Ethiopia. Proposal for a strategic plan for a control program oriented to the export, 10-22 April 2005.p.12-42. 
22. Samuel $A R$ and Knowles NJ. Foot-and-mouth disease type $O$ viruses exhibit genetically and geographically distinct evolutionary lineages (topotypes). Gen. Virol.2001;82:609-621. DOI:10.1099/0022-1317-82-3-609.

23. Ayelet G., Soressa M., Sisay T., Belay A., Gelaye E., Jembere S., Skjerve E., Asmare K. FMD virus isolates: the candidate strains for polyvalent vaccine development in Ethiopia. Acta Tropica. 2013;126: 244-248.

24. Ayelet G, Gelaye E, Jenberie S, Asmare K. Sequence variability in the structural protein-encoding region of foot-and-mouth disease virus serotype A and O of Ethiopian isolates. Res Vet Sci. 2014; 96:558-566.

25. Samuel A. R. (2000): Genetically diverse isolates of type 0 foot-and-mouth disease virus exhibit remarkable amino acid conservation at their neutralising antigenic sites. Pp. 67-78.

26. Menda S, Jenberie S, Negussie H, Ayelet G, Amasalu K. Molecular Epidemiology of Foot and Mouth Disease Virus Outbreaks in Ethiopia in 2011/2012. AJAD. 2014;3:8-16. DOI: 10.5829/idosi.ajad.2014.3.2.85169

27. Negusssie H, Kyule M, Yami M, Ayelet G, Jenberie S. Outbreak investigations and genetic characterization of foot-and-mouth disease virus in Ethiopia in 2008/2009. Trop Anim Health Prod. 2011;43: 235-243. Doi:1007/s11250-010-9683-2

28. Alemu YT. Isolation, molecular characterization and vaccine matching of foot and mouth disease virus circulating in Ethiopia. MSc Thesis Submitted to Addis Ababa University College of Veterinary Medicine and Agriculture, Bishoftu, Ethiopia. 2014.

29. Jemberu WT, Mourits MC, Sahle M, Siraw B, Vernooij JC, Hogeveen H. Epidemiology of foot and mouth disease in Ethiopia: a retrospective analysis of district-level outbreaks, 2007-2012. TransboundEmerg Dis.2016;63:246-259. doi: 10.1111/tbed.12338.

30. Gorna K, Houndje E, Romey A, Relmy A, Blaise-Boisseau S, Kpodekon M, Saegerman C, Moutou F, Zientara S, Bakkali KL. First isolation and molecular characterization of foot-and-mouth disease virus in Benin. Microbiol. 2014;171:175-181. doi: 10.1016/j.vetmic.2014.03.003.

31. .Slager-Bastos AD. Molecular epidemiology and diagnosis of SAT-type foot-and-mouth disease in southern Africa. Doctoral dissertation, University of Pretoria, South Africa.2001.

32. Kassaw K, Afera B, Amasalu K, Hussien D. Serotype identification and molecular characterization of foot and mouth disease in and around Mekelle, Tigray region. Vet. 2013;11:390-394. DOI: 10.5829/idosi.gv.2013.11.4.7699.

33. Sangare O. Molecular epidemiology of foot and mouth disease virus in West Africa. PhD Thesis submitted to the Department of Veterinary Tropical Diseases, Faculty of Veterinary Science University of Pretoria, South Africa.

34. Samuel A, Knowles N, Mackay D. Genetic analysis of type 0 viruses responsible for epidemics of foot-and-mouth disease in North Africa. Epidemiol Infect. 1999;122:529-538.

DOI:1017/s0950268899002265. 
35. Moges S. Vegetation dynamics analysis using normalized differences vegetation index as indicator of restoration or degradation, South Wollo zone, Northern Ethiopia. 2014.

36. Manual of diagnostic tests and vaccines for terrestrial animals. Revue Scientifique Et TechniqueOffice International Des Epizooties. 2008. p. 1092-1106.

37. Foot-and-mouth disease, Manual of diagnostic tests and vaccines for terrestrial animals (mammals, birds, and bees) $7^{\text {th }}$ ed, vol 1, Paris. 2012. P. 145-173.

38. Souley KB, Elliot FM, King DP, Hyera J, Knowles NJ, Ludi AB, Mioulet V, Matlho G, De CK, Thys E, Marichatou H, Issa S, Saegerman C. Outbreak investigations and molecular characterization of footand-mouth disease viruses circulating in south-west Niger. Emerg. Dis. 2018;65:146-157.doi: $10.1111 /$ tbed. 12642 .

39. Tamura K, Stecher G, Peterson D, Flipski A, Kumar S. MEGA6: Molecular Evolutionary GeneticsAnalysisversion6.0.2013;30:2725-2729.doi: 10.1093/molbev/mst197.

\section{Figures}




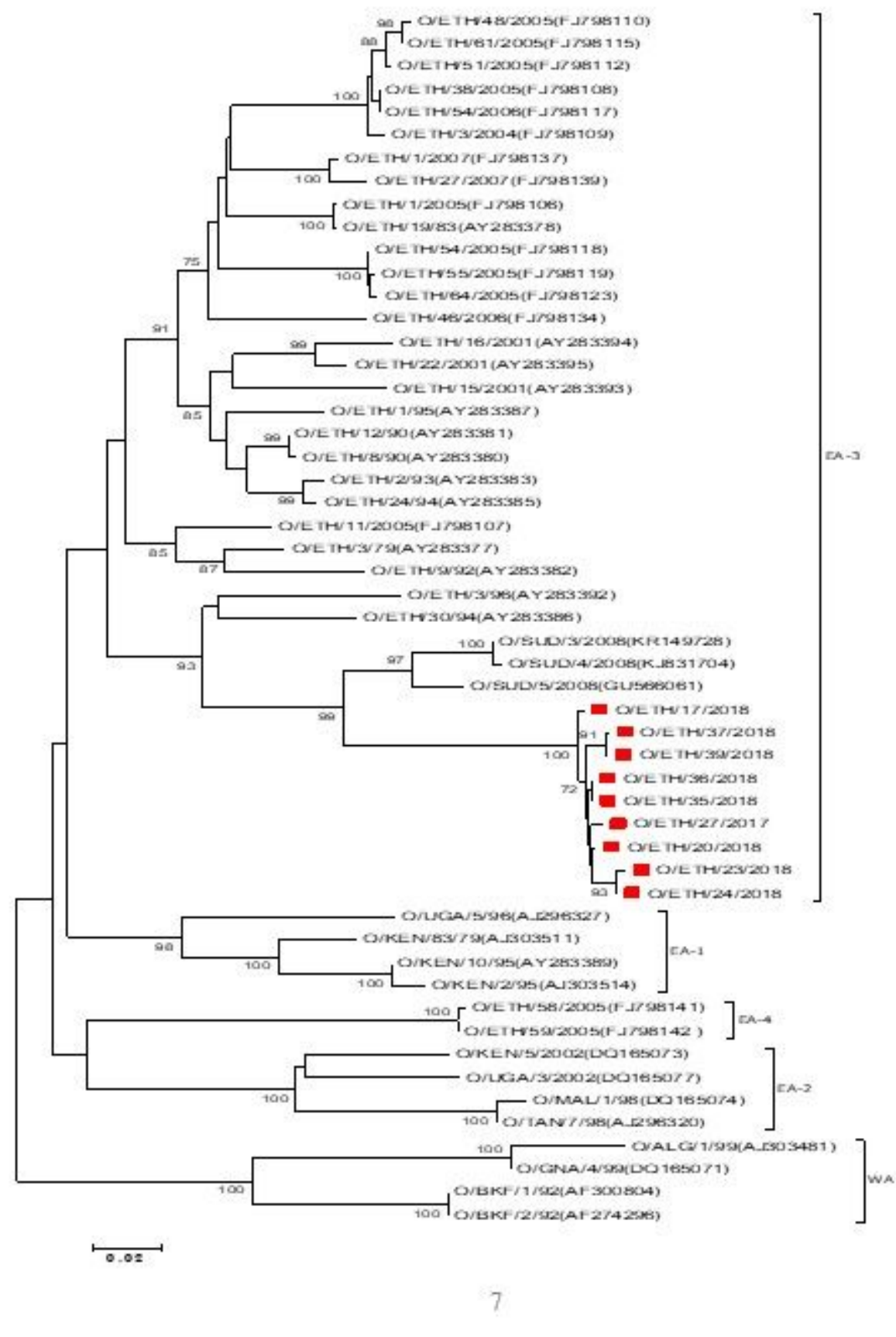

\section{Figure 1}

Minimum-Evolution tree showing the relation between the serotype 0 isolates from Ethiopia and reference viruses. The red rectangle ( ) indicates the new isolates obtained from the outbreak cases of Shewarobit and South Wollo. Bootstrap values $<70 \%$ were not shown in the picture. EA, East Africa; WA; West Africa. 


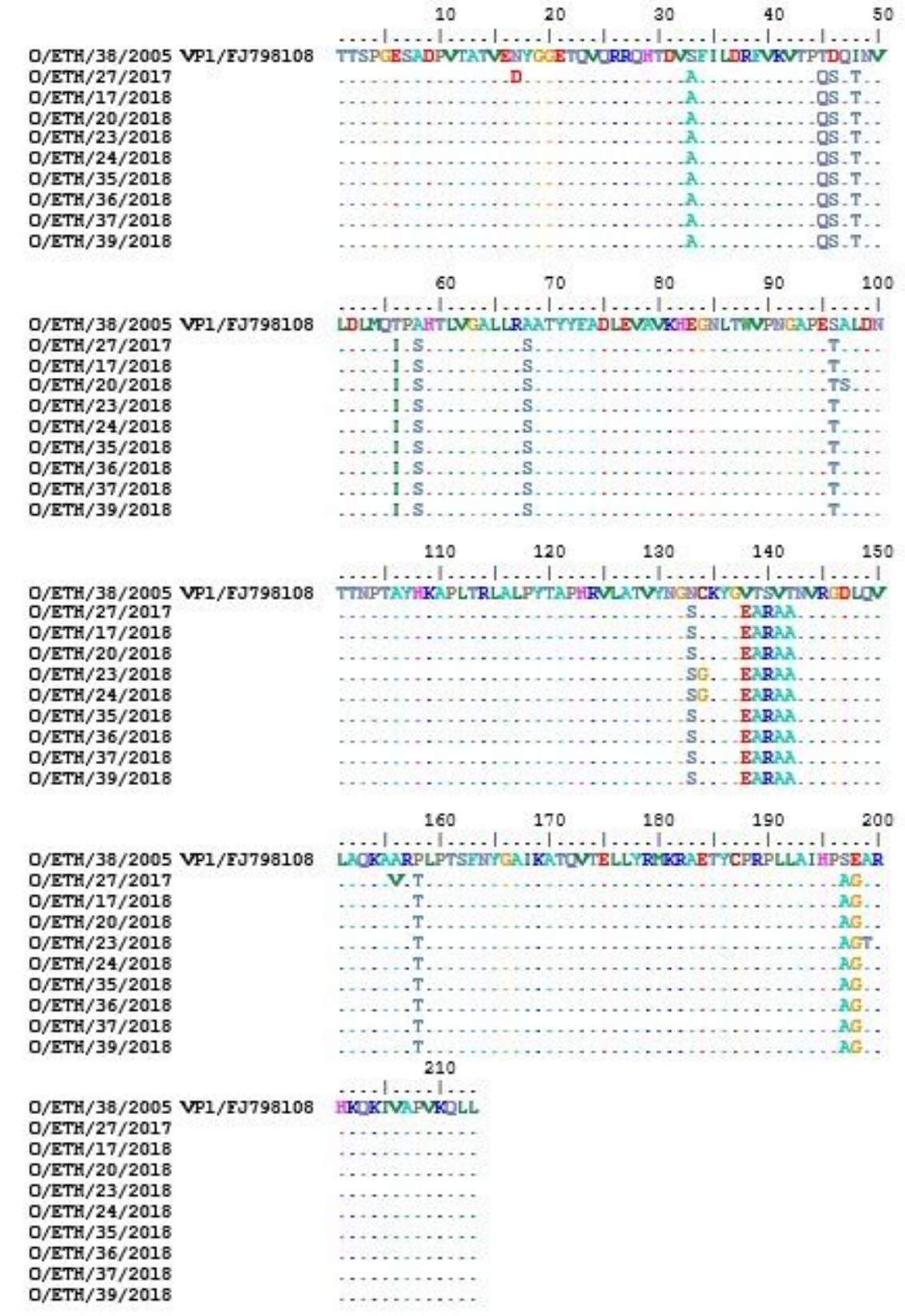

Figure 2

Amino acid sequence alignments of the VP1 gene of vaccine strain (O/ETH/38/2005) with serotype 0 FMD field isolates. The amino acid sequence of the vaccine strain is written on top row and the conserved amino acids are indicated by dots of different colors. 

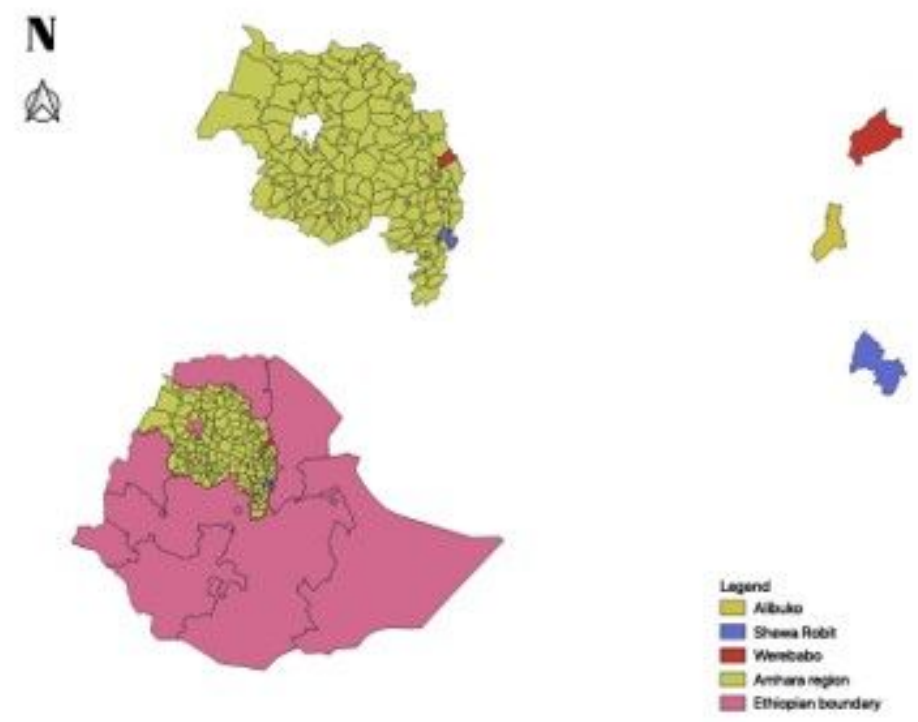

Figure 3: Map of study areas

Figure 3

Map of study areas

\section{Supplementary Files}

This is a list of supplementary files associated with this preprint. Click to download.

- SupplementaryFiles.docx 